\title{
A COMPREENSÃo dA DEPRESSÃo NA População Pobre, uma OcorrênCia maIS (FORTEMENTE) SOCIAL, DO QUE UMA Doença (Fracamente) Clínica
}

\author{
José Francisco Quirino dos Santos ${ }^{1}$ \\ Eunice Nakamura ${ }^{2}$ \\ Denise Martin ${ }^{3}$
}

\begin{abstract}
ResUMo
0 aumento generalizado da depressão aponta para causas sociais e faz com que essa "doença" se desloque do domínio médico para o social. Estudada como ocorrência social, a variedade e 0 alcance dos significados de depressão se revelam quando a doença passa a ser analisada sobre o pano de fundo da sociedade.

0 surgimento de uma nova acepção vulgar, autônoma, saída das relações sociais, começa a merecer atenção especializada. Estudos recentes sobre essa nova conotação, publicados no campo da antropologia médica, evidenciam a existência de uma nova conotação para o termo depressão e as peculiaridades de sua operação no Brasil urbano.

Palavras-chave: Depressão. Significados. Periferia urbana.
\end{abstract}

\begin{abstract}
Absctract
The widespread increase of depression points to social causes and means that this "disease" moves from medical to social field. Studied as a social event, the variety and scope of the meanings of depression appear when the disease is analysed on the background of the society.

The emergence of a new common sense, wich emerges from social relationships, begins to receive specialised attention. Recent studies of this new connotation, published in the field of medical anthropology, highlight the existence of a new connotation to the term depression and the peculiarities of its operation in urban Brazil.
\end{abstract}

Key words: Depression. Meanings. Urban periphery.

\footnotetext{
${ }^{1}$ Departamento de Psiquiatria da Universidade Federal de São Paulo.

${ }^{2}$ Departamento de Enfermagem em Saúde Coletiva da Escola de Enfermagem da Universidade de São Paulo.

${ }^{3}$ Departamento de Psiquiatria da Universidade Federal de São Paulo e Universidade Católica de Santos. Contato: Eunice Nakamura - lefdias@uol.com.br

Endereço para correspondência: Rua Marechal Deodoro, 267 - CEP 08674-070 - Suzano - SP
} 


\section{INTRODUÇão}

partir da década de 1990, relatórios da Organização Mundial da Saúde acerca da
saúde mental e consequiências dos problemas mentais à população, tem apontado
para o aumento da depressão na população mundial, atingindo, nesta mesma década, cerca de 330 milhões de pessoas (OMS, 1999).

0 consistente aumento generalizado da depressão aponta para causas sociais e faz com que essa "doença" se desloque do domínio médico para o social. A doença passa a ser mais bem definida como uma condição social com componentes clínicos e não o inverso.

Segundo Manson (1995) e Fabrega Jr (1974), para compreender a ocorrência da depressão é preciso levar em conta muito mais do que os sintomas expressos pelo paciente, conforme definido clinicamente no discurso médico. "Devem ser considerados os contextos sociais e as forças culturais que modelam o cotidiano, que dão significado às relações interpessoais e eventos na vida." (Martin, Santos e Mari, 2007, no prelo)

Dada a relevância e a atualidade do tema, torna-se necessário compreender 0 fenômeno da depressão, não da perspectiva estritamente clínica que define a patologia, mas de outra, mais profunda, capaz de revelar aspectos sócio-culturais ainda pouco conhecidos desta condição, cada vez mais banalizada nas sociedades ocidentais (Nakamura, 2004).

Estudada "internamente" como ocorrência social, a depressão não revela toda a gama e 0 alcance de suas significações, senão quando posta sobre o pano de fundo da sociedade. É então necessário conhecer a sociedade, seu momento atual, para se entender adequadamente a depressão, pois é nesse contexto que ela revela sua extraordinária importância e deixa transparecer os motivos de sua ascensão estatística.

Ao buscar refletir sobre o tema ressaltando sua dimensão sócio-cultural, o artigo se fundamenta em dois estudos empíricos sobre depressão realizados no campo da antropologia médica: o primeiro, sobre depressão em mulheres (Martin, 2003) e o segundo, acerca da depressão infantil (Nakamura e Santos, 2007). Esses estudos trazem em comum a compreensão dos diferentes significados do fenômeno da depressão elaborados por moradores de bairros periféricos da Região Metropolitana de São Paulo, no primeiro caso, mulheres e, no segundo, famílias de crianças deprimidas.

\section{NEM SÓ A MEDICINA CIENTÍFICA COMPREENDE O CORPO E AS DOENÇAS}

0 corpo e suas mazelas são observados e comentados corriqueiramente pela população nacional, havendo grupos e instituições populares cujo objetivo é invariavelmente a procura do bem-estar. Nesse contexto, a medicina científica, seu olhar 
e suas técnicas, não possui a universalidade e a exclusividade que se imagina, mesmo sendo uma instituição produtora de saúde protegida pelo monopólio legal de ação diagnóstica e curativa. Herzlich (1987, 1991) e Boltanski (1989) são alguns dos autores que se referem criticamente à legitimidade e à autoridade do discurso médico sobre a doença, ressaltando a necessidade de se considerar que os pacientes também mantêm seu próprio discurso, no qual expressam suas representações da doença. Portanto, os demais grupos que operam em saúde concorrem com a medicina, algumas vezes em posição de vantagem, no que tange a relação com sua clientela, pois agregam saberes populares de outras áreas do conhecimento, nem tão precisos, mas indubitavelmente mais palatáveis e inteligíveis para a população em geral.

Todos esses grupos extra-científicos possuem uma característica comum, a magia. Todos eles são liderados por pessoas com atributos especiais, capazes de operar 0 "desconhecido", organizando-o logicamente, de forma a diminuir o sofrimento e a dor de pessoas doentes (Lévi-Strauss, 1975, 2002). Seria de se esperar que esses grupos se apropriassem do vocabulário da medicina, como de fato acontece, não para se associar a ela, mas sim porque dessa forma adquirem maior precisão e legitimidade (por semelhança com uma nomenclatura conhecida), podendo sustentar a comparação com a medicina em termos de eficácia sentida (caso a caso).

Entretanto, o processo inverso não é de se esperar que aconteça, ou seja, que a medicina se sirva de termos do senso comum para designar as doenças, mesmo porque dispõe de exaustivos repertórios de doenças, o mais conhecido e usado sendo o CID (Classificação Internacional das Doenças) (OMS, 1995), que já chegou à sua décima versão. Muito menos seria de se esperar que a definição sintomática de alguma doença, de qualquer doença, fosse adquirida do ideário do senso comum. Entretanto, esse parece ser o caso de uma das doenças de grande incidência no mundo de hoje, a depressão.

\section{Principais ConotaÇões téCNiCAS do termo}

A ciência médica reconhece a existência de uma condição particular de saúde prejudicada, a depressão, cuja principal característica, que lhe empresta o nome, também é reconhecida pela opinião laica em geral, mostrando uma apropriação pelos leigos em geral, num processo rapidíssimo. 0 termo, embora conhecido por séculos, foi incorporado ao vocabulário médico corriqueiro há poucas décadas, substituindo antigas denominações de doenças às quais correspondiam outras tantas concepções de corpo e de mente, de alma ou espírito. Na psicanálise, a incorporação é mais antiga, desde o início do século XX, mas com conotações que se foram alterando no decorrer do tempo. 


\section{CONOTAÇÃo MÉDica do TERMO}

Está montada sobre a etiologia da doença, portanto, eminentemente biológica. Enuncia a doença através de sintomas perceptíveis descritos no Manual Diagnóstico e Estatístico de Transtornos Mentais (DSM IV: F32) e acentua seus aspectos organolépticos passíveis de tratamento clínico através de drogas (DSM IV, 1995). A doença se apresenta como um desvio do "projeto" biológico do homem, sendo portanto de ocorrência universal na espécie humana, e considerada como exceção (do projeto normal). A esta conotação, aplica-se por excelência a quantificação estatística da epidemiologia. Adepressão tornase, nesse sentido, uma ocorrência de massa, conferindo ao termo outra conotação dentro do campo médico, a da doença minuciosamente descrita por seus sintomas e por sua distintiva representação químico-molecular.

\section{CONOTAÇÃO PSICANALÍTICA DO TERMO}

Na verdade há várias conotações. Entretanto, para os propósitos deste texto, podese selecionar a conotação geral freudiana, posteriormente modificada por vários autores, da depressão como perda (Delouya, 2000), sofrida pelo individuo, mas tratada como sendo a supressão do espaço de gozo, segundo Klein (Klein apud Delouya, 2000).

Essa conotação sublinha a experiência, ante e pós-natal, de si com o mundo, como impregnadora das trocas que caracterizam o ser, visto como parte de uma espécie eminentemente coletiva. A continuidade dessa troca se liga à continuada recompensa pelo gozo sensorial, motor e afetivo. A depressão, nesse contexto, significa cessação, corte, interrupção, de uma condição anterior diferente, na qual o desejo do indivíduo tinha objeto e se processava, de alguma forma. A linha central dessa conotação está na relação aproveitadora do individuo com o mundo e como ele se constrói internamente a partir dela, em termos de cessão e gozo, pólos equilibrados cuja rupturaé recusada, pois perturba e estraga o todo, a depressão sendo a expressão sensível dessa ruptura.

\section{UMA NOVA CONOTAÇÃO, FORA DA CIÊNCIA}

0 processo de banalização do termo, que vem ocorrendo há algumas décadas, trouxe modificações profundas no campo de significações que abrange. Os aspectos sociais da depressão, que sempre existiram e sempre foram reconhecidos, mudaram de contexto, nesse processo vulgarizador. Deixaram de ser outro componente do termo para se tornar uma acep̧̧ão própria e autônoma. Isso significa que o termo pode ser usado também exclusivamente em seu sentido social, o emissor (pessoa) não necessitando conhecer as outras acepções (psicanalítica, epidemiológica etc.), nem sequer saber que estas existem, para empregar o termo e se fazer compreender.

316 • MEDiaçōes, LondRINA, v. 12, N. 1, P. 313-322, JAN/JUN. 2007 
Esse acréscimo de uma área de significação do termo trouxe consigo a possibilidade da generalização e talvez a universalização dessa acepção. Entretanto, à medida que se espraia essa conotação, o termo se afasta das acepções anteriores e se torna difícil de ser manejado pela ciência.

0 componente social das conotações epidemiológica, psicanalítica outras, sempre reconhecido, indicava haver vínculos fortes entre a depressão e certos aspectos societários. Tais vínculos figuravam ocasionalmente nos estudos e definições, mas com importância diminuída. Eram um arrimo de significações. Não eram estudados como objeto principal.

\section{A ABORDAgem do teMA PELA ANTROPOlOGIA MÉDiCA}

0 surgimento da nova acepção vulgar, autônoma, saída das relações sociais, começa a merecer atenção especializada. Dois estudos sobre essa nova conotação foram realizados no campo da antropologia médica, em bairros periféricos da Região Metropolitana de São Paulo (Nakamura e Santos, 2007; Martin, 2003). Esses bairros expressam aspectos que caracterizam os países periféricos, entre os quais se inclui o Brasil, situados fora dos grandes caminhos da economia mundial e constituídos por uma sociedade urbana recente, socialmente numerosa e cronicamente desempregada (desqualificada) em suas franjas mais pobres. As descobertas feitas por esses dois trabalhos confirmam completamente a existência de uma nova conotação para o termo depressão e mostram as peculiaridades de sua operação no Brasil urbano, deixando claras, também, certas características da relação entre medico e paciente, de grande importância para a compreensão do todo.

Nas linhas que seguem, resumem-se os pontos principais desses dois trabalhos, suas justificativas e seus achados.

No trabalho de Nakamura e Santos (2007), o tema é a criança com diagnóstico confirmado de depressão, nafaixa de seis a 12 anos. Os contatos foram feitos no ambulatório de psiquiatria da infância e da adolescência do Hospital de Clínicas da Faculdade de Medicina da Universidade de São Paulo e as entrevistas foram realizadas com os pais dessas crianças, em seus domicílios, tendo como universo a Grande São Paulo. Essas famílias tinham em comum o fato pertencerem à classe mais pobre, serem moradores da periferia e utilizarem um serviço público de saúde para o tratamento de seus filhos atingidos pela depressão. Paralelamente, foram entrevistados também vários profissionais de saúde do mesmo serviço, em especial psiquiatras, conhecedores das crianças e de seus pais selecionados para o estudo. Esse tipo de coleta de dados, realizado empiricamente, com pessoas afetadas, e durante a etapa aguda da crise provocada pelo inicio de intervenção médica, é particularmente revelador dos comportamentos e sentimentos dos envolvidos, permitindo recolher falas e atitudes de outra forma invisiveis. 
0 principal resultado desse estudo empírico foi o enunciado claro da conotação concreta da depressão como doença e, a partir daí, a descoberta e exposição de certos mecanismos sociais complexos, que contribuíram para tornar essa doença amplamente conhecida e vulgarizada, afastada da sua conceituação médico-científica, conforme se observa nos depoimentos dos psiquiatras e das famílias entrevistadas.

No depoimento dos psiquiatras, uma noção particular de depressão infantil é expressa. Ao rotularem determinados comportamentos infantis como doença e prescreverem o tratamento, esses profissionais explicitam uma noção de depressão infantil que remete à idéia de adaptaç̃̃o e de ajuste. Para eles, a depressão infantil está vinculada a um "mau funcionamento" das crianças, garantindo-se a possibilidade de intervenção, segundo a lógica médico-científica.

"Muitas vezes [o psiquiatra] é criticado quando traz um tratamento ou a gente tenta medicar, procura fazer um tratamento mais incisivo. O pessoal fala que assim, que a gente só está preocupado em melhorar as partes externas, que aí agrada a mãe, agrada a sociedade, etc., mas eu não vejo isso porque a criança não é burra, ela sabe que se ela não esta conseguindo ir na escola, isso tem reflexo na auto estima dela, ela não tem problema em ir pra escola, ela não está querendo lutar contra a sociedade, a única coisa dela é que ela queria ir bem só que ela não está indo bem [...]" (Psiquiatra)

A noção de depressão infantil expressa nos depoimentos das famílias das crianças deprimidas não possui nenhuma relação com os critérios médicos de classificação da doença, mas vincula-se a uma certa insatisfação e desconforto em como lidar com determinadas incertezas da vida, dentre as quais incluem certos comportamentos infantis considerados diferentes e estranhos.

"[...] eu falei pra doutora: 'prá ser sincera, eu não sei o que é a depressão, se está sendo depressão, se está sendo manha dele, se está sendo malandragem dele', tem momentos que não sei o que é realmente a depressão. Que eu entendo é uma coisa triste." (Família de criança deprimida)

Essas diferentes conotações revelam que a idéia de depressão pode ser suficiente ampla e vaga para possibilitar a vulgarização do termo, cumprindo, ao mesmo tempo, uma função importante e necessária de comunicação entre médicos e familiares de pacientes, integrantes de uma mesma sociedade e cultura.

Os discursos dos pais e dos profissionais de saúde, como apontado neste estudo revelam a impropriedade de uma noção única de depressão infantil, aquela definida pelo discurso médico-científico como doença. Esses discursos tornam evidente a amplitude e 
imprecisão do termo, o que permite que esses diferentes significados da doença não sejam totalmente incompatíveis entre si, cumprindo assim uma necessidade de comunicação, mesmo que momentânea.

No trabalho de Martin (2003), o alvo do estudo ali retratado são mulheres da periferia pobre de uma metrópole, São Paulo. Foram realizadas mais de 30 entrevistas com psiquiatras e pacientes, em postos de saúde afastados, em bairros-dormitórios repletos de desempregados, nos quais a agressividade atinge padrões inéditos e sua principal conseqüência sentida, a violência interpessoal, freqüentemente conduz a litígios que resultam em morte (Martin, Mari e Quirino, 2006, no prelo).

Das entrevistas feitas, 11 foram aproveitadas pela riqueza de enunciado pelas mulheres e 5 entre aquelas com os médicos que as tratam.

"A falta de condução, falta de emprego e também as drogas, malandragem que é muita é demais aqui, tem demais mesmo como diz a Dra. X, já foi provado que aqui é o lugar que tem mais bandido do que nos outros lugar no mundo inteiro isso tudo da medo na gente, é acho que épor isso que a gente fica com a cabeça ruim quase todas as mães hoje em dia esta com depressão, ta com um problema, ta com outro." (Mara)

"[...] vem de quando eu me separei dele, a pra falar pra senhora eu acho que eu tenho esse problema desde quando eu vim do norte porque eu fiquei longe da familia, longe do meu pai, da minha mãe de todas as minhas familias ele sempre desde quando eu me casei com ele que ele sempre judiava de mim, sempre batia em mim, sempre me traiu." (Gilvanete)

"Olha essa depressão começou quando eu percebi que o meu marido tava me traindo, então não foi acho que porque eu amava tanto mais eu achei uma injustiça entendeu." (Cida)

Oprincipal resultado, no que respeita à ocorrência de depressão, estána generalização do termo, usado coloquialmente e com grande familiaridade pelas entrevistadas. 0 segundo resultado importante está na conotação nova que o termo assumiu, vulgar e simplificada, que se distancia da noção de doença e se aproxima muito de um estado d'alma, de uma baixa auto-estima persistente. Invariavelmente, as entrevistadas, entre queixosas e irritadas, fazem menção da sua situação familiar como uma progressão no caminho da derrota e do rebaixamento social. Décadas atrás, a consciência de si e da sua condição miserável seria outra, voltando-se contra a injustiça e a fome, com indignação. Hoje, o que revelou esse estudo foi um padrão recentemente estabilizado de auto-estima ferida, foi também a autonomia de reivindicação de seu estatuto de mulheres que não são mais amparadas por antigos esquemas machistas, hoje desgastados. 
Esse estudo, ao revelar uma nova conotação do termo, tão familiar apesar de recente, mostra também um inquietante espraiamento incontido dessa mais-que-doença, queéuma verdadeira condição político-social, que engloba novas pessoas com assombrosa rapidez e as acostuma a pensarem em si como pacientes de uma nova classe de doença rebaixadora, a depressão. Essa conotação é claramente comunitária e permite às pessoas (as mulheres entrevistadas) se colocarem num nicho social reservado aos doentes, pelo menos por algum tempo, até que surja alguma oportunidade de trabalho. Curiosamente, ao conseguirem isso, a doença não desaparece, torna-se suportável, pois recebe um nome, depressão. Nessa conotação, como mostra Martin, há um componente masculino de irresponsabilidade e omissão, porém descrito por elas de maneira menos peremptória e dando conta da questão da culpa, que é empurrada para fora de si, em geral para 0 companheiro e para as condições pobres e violentas em que vivem.

De acordo com esses estudos, longe de ocorrer aleatoriamente incidindo sobre quaisquer indivíduos submetidos aos mesmos constrangimentos inescapáveis de vida, e justamente aqueles que, embora indesejáveis, são os que os integram à sociedade, a depressão é a doença dos indivíduos particulares que, por não poderem alterar o quadro objetivo de sua existência, escolhem, em geral involuntariamente, a via da doença para continuar o seu viver. Deve-se ressaltar, nesta altura, que tal escolha não é realizada no plano da consciência, mas sim profundamente, surgindo "apropriadamente" na mente como condição resultante (de causas mal formuladas ou inteiramente desconhecidas), ligada a distanciamentos sociais, a alvos inatingíveis, a defeitos e erros, que na consciência se sedimenta como estado de prostração e perda de estímulos, de desistência e, sobretudo, de desencanto com o mundo.

\section{Conclusão}

Compreender os mecanismos sociais e políticos que levaram a noção cientifica de depressão a ser metamorfoseada a ponto de se converter em uma nova conotação, a mais difundidae a menos precisa, éuma tarefa que demanda um exercício considerável de abstração:

a) em primeiro lugar, a depressão é uma doença especial. Ela escapa à idéia vulgar de doença, pois não ataca o corpo, nem o "estraga", como fazem as doenças em geral, mas age sobre o espírito, que habitualmente é o domínio da religião. Nenhuma outra doença age assim, portanto, a depressão é especial.

b) a depressãoé, nesse aspecto, um mecanismo de transferência de resultados. De uma situação objetiva desagradável ou inaceitável, ela permite passar para o plano pessoal, subjetivo, da mente de cada um. Nesse plano, ela opera o mundo real atual em certos aspectos novos, mais adequados e eficazes, não abrangidos pela religião. 
Fica claro que a depressão não éo refugio dos excluídos, ela éo encaminhamento social da questão, num momento de inexistência de uso do referencial tradicionalfamiliar para a vida, revelando uma impossibilidade ou dificuldade de operar o mundo usando as ferramentas cognitivas disponíveis e a própria bagagem cultural. Nesse sentido, a depressão é uma forma contemporânea de se encaminhar uma consciência doente. Trata-se de um encaminhamento porque: a) é reconhecida pela autoridade (o médico) que a trata com remédios (de uso autorizado, produzido por linhas específicas para isso, em laboratórios estabelecidos e de seriedade reconhecida); b) em decorrência, essa conotaçãa popular já foi incorporada à sociedade e nela permanece como "saída médica" eficaz, altamente, para questões de exclusão socioeconômica; c) essa solução auxilia a manutenção da estabilidade social e política, reconduz a insatisfação dos excluídos para dentro da sociedade através da sua classificação como doentes.

Portanto, enquanto ocorrência de interesse médico a depressão, como qualquer outra doença do gênero, não escapa de sua incidência estatística sobre a população, como ela foi estabelecida pela epidemiologia. Entretanto, pela via de sua conotação popular, amplamente difundida e usada, a depressão vem conhecendo uma taxa de crescimento que a aproxima das doenças epidêmicas, tal é o número de pessoas que se declara em depressão.

Do ponto de vista da ciência, a imprecisão generalizada causada pela conotação popular de depressão deverá conduzir ao isolamento de certos sintomas que possam ser usados na triagem dos casos clínicos, deixando-se a conotação popular e seu tratamento clinico como uma classe de mal social e culturalmente necessário.

Para a antropologia, entretanto, a persistência dessa conotação trás ao debate 0 caso raro das culturas cujos membros (que as criam e recriam, por suas ações cotidianas) não estão satisfeitos e inevitavelmente mudarão as condições de sobrevivência, para patamares menos inconfortáveis. 


\section{REFERÊNCIAS}

BOLTANSKI, L. As classes sociais e o corpo. 3. ed. Rio de Janeiro: Edições Graal, 1989. (Biblioteca de saúde e sociedade, v. n. 5).

DELOUYA, D. Depressão. São Paulo: Casa do Psicólogo, 2000.

DSM - IV. Manual Diagnóstico e Estatístico de Transtornos Mentais. 4. ed. Porto Alegre: Artes Médicas Sul, 1995.

FABREGAJr, H.. Problems implicit in the cultural and social study of depression. Psychosomatic Medicine, 36, n. 5: 377-397,1974.

HERZLICH, C. Santé et maladie: le point de vue sociologique. Entrevista de Maria Teresa de Oliveira. Cadernos de Saúde Pública. Rio de Janeiro, v. 3, n. 3, p. 306-314, 1987.

- A problemática da representação social e sua utilidade no campo da doença.

Physis - Revista de Saúde Coletiva, v. 1, n. 2, p. 23-36, 1991. (A representação na saúde coletiva).

LÉVI-STRAUSS, C. Antropologia estrutural. Rio de Janeiro: Tempo Brasileiro, 1975. (Biblioteca Tempo Universitário, 7).

0 pensamento selvagem. 3. ed. Campinas, São Paulo: Papirus, 2002.

MANSON, S. M. Culture and Major Depression. Current Challenges in the Diagnosis of Mood Disorders. The Psychiatrics Clinics of North America,1995:18, 3, Sept.. 487-501.

MARTIN, D. "Depressão em mulheres na periferia de São Paulo: um olhar antropológico". Ciência \& Saúde Coletiva, Rio de Janeiro, v. 8, p. 1-7, 2003.

MARTIN, D., MARI, J. J, QUIRINO, J. "Views on depression among patients diagnosed as depressed in a poor town in the outskirts of São Paulo, Brazil". Transcultural Psychiatry (no prelo).

MARTIN, D., MARI, J. J, QUIRINO, J. "Depressão entre mulheres na periferia de São Paulo". Revista de Saúde Pública, v. 41, n. 4, 2007 (no prelo).

NAKAMURA, E. Depressão na infância: uma abordagem antropológica. São Paulo, 1995. Tese (Doutorado em Antropologia Social) - Faculdade de Filosofia, Letras e Ciências Humanas, Universidade de São Paulo.

NAKAMURA, E., SANTOS, J.Q. "Depressão infantil: abordagem antropológica". Revista de Saúde Pública, v. 41, n.1, p. 53-60, 2007.

ORGANIZAÇÃO MUNDIAL DA SAÚDE - OMS. Classificação Estatística Internacional de Doenças e problemas relacionados à saúde (CID-10). 2. ed. São Paulo: Edusp, 1995.

ORGANIZAÇÃO MUNDIAL DA SAÚDE - OMS. "The 'newly defined' burden of mental problems”. Fact Sheet, n. 217, april 1999. Disponível em: http//www.who.inf/inf-fs/eh/ fact217.html 